\section{Common sports injuries: from evidence to practice}

\author{
Gavan White
}

The ability of doctors in primary care sports medicine to sift the evidence about the diagnosis and treatment of sporting injuries, identify the 'truth' and then implement this into clinical practice is limited by time and resources. This is especially true in rural areas or in the primary care setting where resources are sparse and specialised personnel are scarce. The primary care practitioner may be conflicted between time spent consulting and the need to sift through papers to find important new clinical practice research.

Review articles can do the hard work and synthesise the clinical evidence. Despite excellent reviews, the research just may not be there to help guide our clinical practice. In such times, we tend to fall back on the experience and expertise of those around us; both physically and through electronic resources and social media.

We are extremely fortunate that BJSM provides everything from research articles, review articles, editorials, consensus statements, through to podcasts, blogs and videos. Rural general practitioners and club doctors in isolated areas have access to these resources that can guide their clinical practice.

This issue concentrates on shoulder and groin injury-common sporting injuries that have diverse recommendations for management. It includes papers that challenge clinical practice and common beliefs. In addition, papers are included that are important to reinforce the importance of exercise in our fast and complex world.

\section{SHOULDER}

Shoulder pain is managed by many sports practitioners from various clinical backgrounds. Research into these different treatment approaches can highlight what really does work and demonstrate the lack of efficacy of some treatments. These positive and negative findings should assist clinical decision-making, however research often fails to change clinical practice.

Correspondence to Dr Gavan White, Rural Clinical School, University of Western Australia, PO Box 1219, Bunbury, WA 6231, Australia;

gwhite@synergy-sports.com.au
Two well held clinical beliefs in shoulder impingement are tested and found wanting. The paper by Ratcliffe et al (see page 1251) finds that scapular orientation does not influence the incidence of impingement syndrome. Similarly, Leininger et $a l^{1}$ found that glenohumeral joint mobilisation did not augment an exercise programme for shoulder impingement. These two papers add significantly to our understanding about treatment of shoulder impingement. Gebremariam et al (see page 1202) and the review by van den Dolder et al (see page 1216) confirm that the ideal management programme for shoulder impingement syndrome is not known. Review of the management of shoulder dislocation by Dala-Ali et al (see page 1209) affirms the need to maintain an up-to-date knowledge and practice for sporting injuries.

\section{GROINS}

The problematic and enigmatic groin pain is a condition that causes frustration at the primary care level. It has many names, purported causes and a myriad of treatments. It is also common, Hölmich et al (see page 1240) found that 'adductor' type groin injury was found to be the most common groin presentation in a cohort of 998 subelite soccer players followed for a full season. The authors also demonstrate that hip joint morphology is unrelated to the development of 'adductor' type groin pain.

\section{THE MINIMALIST SHOE}

Runners are faced with decisions about footwear and doctors may be asked for their opinions about these options. One recent trend relates to the minimalist shoe. The article by Ryan et al (see page 1257) gives some very valuable information, showing that injury rates were lowest in runners using a neutral shoe, highest in the partial minimalist shoe, with the full minimalist shoe causing an increased rate of shin and calf pain.

I also encourage you to read the article by Weston et al (see page 1227) who demonstrate that high-intensity training benefits cardiorespiratory fitness, also Janssen et al (see page 1235) who show ankle bracing to be better than neuromuscular training in preventing ankle injuries.

\section{SPORTS DOCTORS AUSTRALIA}

Sports Doctors Australia practitioners are involved in team care and sports medicine, often from within a general practice environment. As a group, we supply primary care sports medicine to thousands of people throughout Australia. Our group promotes a collegiate base for members as well as supplying valuable education through State and National seminars, conferences and training opportunities.

The time and energy required to filter research in a modern, busy work environment challenges primary care sports doctors. Furthermore, sports doctors in Australia provide excellent sports medicine care from within the increasingly complex environment of general practice. Each practitioner needs different information and training and it is this challenge that we, as a group, deal with on a daily basis.

It is with this in mind, that we will, again, be very active in the Australian Conference of Science and Medicine in Sport (ACSMS) in Canberra this year. This conference is of world standard, bringing together injury prevention, health promotion, research and practical teaching to a large multidisciplinary group of attendees. This conference, Be Active 2014, is being held in Australia's capital, Canberra, on 15-18 October 2014. I encourage all sports doctors to attend this annual conference to get a true multidisciplinary taste of new knowledge and practice.

\section{Competing interests None.}

Provenance and peer review Not commissioned; internally peer reviewed.

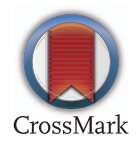

To cite White G. Br J Sports Med 2014;48:1199. Accepted 27 March 2014

Br J Sports Med 2014;48:1199. doi:10.1136/bjsports-2014-093714

\section{REFERENCES}

1 Leininger $\mathrm{BD}$, Kamper SJ. No strong evidence that the addition of joint mobilisation to an exercise programme improves outcomes for shoulder dysfunction. Br J Sports Med 2014;48: 1196-7. 